\section{International Scientific Journal Theoretical \& Applied Science}

p-ISSN: 2308-4944 (print) e-ISSN: 2409-0085 (online)

Year: 2017 Issue: 02 Volume: 46

Published: 28.02.2017 http://T-Science.org
Husan Anvarovich Djurakulov

Senior Researcher Degree-seeking student of Samarkand State University Samarkand City, Republic of Uzbekistan. djurakulov-84@mail.ru +99893-334-85-31

SECTION 30. Philosophy.

\title{
THE ROLE OF ECOLOGICAL LEGAL THINKING AND CULTURE TO ENSURE THE ENVIRONMENTAL SAFETY
}

Abstract: This article is conducted to investigate the role of environmental awareness and culture to ensure the environmental safety and the elimination of global, regional and national issues of the day.

Key words: ecology, human, legal, environmental legal consciousness, ecological culture, ecological safety.

Language: Russian

Citation: Djurakulov HA (2017) THE ROLE OF ECOLOGICAL LEGAL THINKING AND CULTURE TO

ENSURE THE ENVIRONMENTAL SAFETY. ISJ Theoretical \& Applied Science, 02 (46): 5-9.

Soi: http://s-o-i.org/1.1/TAS-02-46-2 Doi: crossef https://dx.doi.org/10.15863/TAS.2017.02.46.2

\section{РОЛЬ ЭКОЛОГИЧЕСКОГО ПРАВОВОГО СОЗНАНИЯ И КУЛЬТУРЫ В ОБЕСПЕЧЕНИИ ЭКОЛОГИЧЕСКОЙ БЕЗОПАСНОСТИ}

Аннотация: В данной статье обсуждается исследование роли экологического правосознания и культуры в обеспечении экологической безопасности и устранении глобальных, региональньх и национальных проблем сегодняшнего дня.

Ключевые слова: экология, человек, правосознание, экологическое правосознание, экологическая культура, экологическая безопасность.

“Борьба за экологию, чистоту окружающего пространства-является всеобщей борьбой всех стран и народов, живущих на этой планете....”[1, с.109 ].

Ислам Каримов

\section{Introduction}

К XXI веку задачи экологической безопасности в качестве одной из глобальных проблем охватили очень широкие стороны взаимоотношений человека с окружающей природной средой. В результате, из-за того, что указанные проблемы касаются не только определённого государства, но судьбы всего человечества, превратились в одно из направлений межгосударственной политики.

\section{Materials and Methods}

Нам известно, что термин “экология” введён в науку 1866 году немецким учёным Эрнестом Геккелем (экология являясь греческим словом обозначает oikos-дом, жилище и logos - учение), по его мнению экология изучает все необходимые для жизни процессы живых организмов с окружающей средой. А при этом в первую очередь.важную роль играет отношение человека к природе. Так как человек являясь частью природы, на сегодняшний день он является разумным существом, находящимся на уровне влияния на природу. То есть, нельзя отрицать, что с развитием общества растёт и влияние человека на окружающую среду. Действительно и то, что происходит взаимное общение человека с природой, растительным и животным миром, а также с подземными и наземными богатствами. Наряду с этим, когда экологические проблемы увеличиваются и в настоящее время решение этих проблем является актуальной задачей для человечества, несравнима роль в основном, экологического сознания, экологического правосознания и экологической культуры.

В условиях финансово-экономического кризиса, происходящего в мире требует 
административно-правовым путём осуществлять восстановление экономики в соответствии с экологической стабильностью, расширять полномочия государств в области управления экологией. Потому, что для экологического воспитания и формирования навыков в этой области у людей, не имеющих экологического правосознания, знания и навыков, а также ведущих деятельность с "потребительским" мировоззрением, требуется определенный срок. В свою очередь, ожидание такого периода восстановления может нанести большой вред экологической безопасности

Следует отметить, что система охраны окружающей природной среды включает в себя широкий круг мер, в котором одним из главных факторов считается формирование экологического правосознания и культуры общества и граждан. Таким образом, состояние окружающей природной среды зависит, в первую очередь, от поведения людей, от степени использования ими природных богатств и ресурсов. При этом, ключевым фактором в определении поведения людей считаются их взгляды, убеждения и познания, взаимосвязанные c различными областями их общественной жизни. Данное состояние требует более глубокого изучения явления правосознания в качестве фактора, влияющего на поведение личности в правовом или противоправном направлении. В связи с этим, исследование задач, связанных с природой экологического правового сознания, которая является составной частью правосознания граждан, приобретает важное значение в системе обеспечения экологической безопасности. Нигилистическое отношение к роли и месту права в обществе не оставило без негативного влияния на суть и содержание социальной связи в области экологии. В настоящее время, когда потребительские интересы ставятся выше требований правовых норм и интересов охраны окружающей природной среды можно добиться эффективной деятельности по обеспечению механизма экологической безопасности, путём повышения экологического правосознания граждан. При этом, стоит отметить существование различных подходов, связанных с пониманием экологического правового сознания в предметах экологии и правоведение.

Как утверждал СмирновТ.С., на сегодняшний день экологизация форм общественного сознания, находит своё отражение во влиянии его на экономические, политические, правовые, эстетические формы сознания [2, с.74]. По мнению Долгополова Л.Д. и Долматова Н.И., экологическое правосознание не является самостоятельной формой общественного сознания, а проявляется в виде переплетения правового и экологического сознания [3]. В отличие от вышеизложенного подхода, Вершок И.Л. считает, что глобальные изменения, происходящие в природе и обществев настоящее время, требуют отдельного изучения некоторых направлений из состава правосознания. Особенно, по её мнению, возникающие риски и проблемы в результате глобального экологического кризиса,ставят перед обществом принципиально новые и новые задачи. Суть данных задач состоит в осознании проблем, связанных с использованием природы и охраной окружающей природной среды, а также то, чтоэкологические правонарушения, вызываютпоследствия опасные для жизни; реальном оценивании существующей экологической ситуации; детальном изученииправ и обязанностей гражданв области использования природы и охраны окружающей природной среды [4, с.42].

Если обеспечение экологической безопасности является актуальным вопросом, стоящим перед мировым сообществом, это требует разработать социально-экономический и правовой механизм, повысить ответственность за охрану здоровья людей, осуществлять новые проекты и меры.

В связи с этим, сегодня требуется то, чтобы дать населению глубокие знания по экологическому праву, усовершенствовать системы экологического образования, проповедования и воспитания на основании современных требований и на основе этого добиться развития экологической правовой культуры, или в полном смысле этого слова требуется формирование экологического правосознания.

Таким образом, сегодня теоретико-правовые аспекты исследования задач, связанные с развитием правосознания общества, в том числе экологического правосознания и культуры имеет не только научное, но и практическое значение.

Следует отметить, что государственная политика по формированию и развитию экологического правосознания населения полагается на основные правила такие, как первостепенность экологического права и свободы граждан, верховенство Конституции и законов, научность, последовательность и общность юридического образования и воспитания, прозрачность экологической правовой информации, а также особое отношение к экологическому правовому воспитанию и грамоте.

Принятие и внедрение в жизнь нормативноправовых актов, касающихся правосознания и культуры граждан означает, с одной стороны, они являются ярким показателем того, что общество становится более просвященным, развитым, с 
широким правовым кругозором, с другой стороны, это означает, что данные документы, о создании надежной и прочной правовой основы для эффективного осуществления государственной политики по развитию экологического правосознания и улучшению правового воспитания населения. Возникновение процессов интеграции научного познания и междисциплинарных проблем, в свою очередь, создаёт условия для возникновения особого типа экологического сознания явления экологического правосознания. Во многих философских, социологических и юридических исследованиях при описании взаимоотношений личности к природе использованы различные категории. В частности, "социальноэкологическое сознание", "социальноэкологическая культура", "экономическое и экологическое мышление", "социальноэкологическое самосознание", "экологическое мировоззрение", "отношение общества к природе", "духовное состояние человека по отношению к природе" и другие.

По мнению белорусской учёной Вершок И.Л., которая проводила научные исследования по вопросам экологического правосознания, дефиниции между данными понятиями во многих аспектах, связаны с осознанием экологической действительности в обычной и специальной форме [4, с.42]. В то же время, возникновение определённой непоследовательности в отношениях между природой и обществом и задач, связанных с использованием природных ресурсов, если принимать во внимание регулирование с основными правовыми нормами почти во всех странах мира, следует отметить, что экологическое правосознание в вышеуказанной системе категорий занимает важное место. То есть, если брать во внимание что поведение человека, связанное с окружающей его природной средой осуществляется в рамках экологических правовых норм, то требуется оценивать его отношение к природе с правовой или неправовой точки зрения. Необходимость исследования ситуации «Экологического правосознания" прежде всего связано с серьёзным воздействием к обеспечению безопасности, в том числе экологической безопасности.

В связи с этим, детальное исследование юридической природы экологического правосознания и его проявляющихся особенностей на сегодняшний день считается одной из актуальных функций.

Следует отметить, что экологическая ситуация настоящего времени объясняется отсутствием возможностей обеспечить естественным путём гармоничности природы и общества. Обеспечение природной стабильности во многом зависит от характера антропогенной деятельности, а также от степени его соответствия к экологическим требованиям. В связи с этим, первый президент Республики Узбекистан Ислам Каримов справедливо отметил, что "Наука и технология развиваются быстрыми темпами и при сегодняшних меняющихся условиях географо-политической структуры мира, такие проблемы как регулирование оказываемого влияния человека на биосферу, гармонизация взаимодействия социального прогресса и сохранения удобной природной среды, достижение равновесия во взаимоотношениях между человеком и природой, становятся все более актуальными [5, с.109 ].

Следует особо отметить, что на современном этапе развития человечества экологические проблемы оказывают своё влияние на все формы общественного сознания (моральную, политическую и правовую). Но это вовсе не означает, что экологическое сознание это обобщённость социальных форм сознания. Оно выполняет специальные функции, которые не могут осуществлять другие формы общественного сознания. При этом, оно выражает своеобразную социальную потребность, то есть функцию обеспечения гармонии в связи общества и природы. Экологическое сознание в решении данной задачи, конечно же, будет в тесном контакте с другими формами общественного сознания, в том числе, правовым, духовным, политическим, религиозным сознаниями. При этом нужно отметить, что экологическое сознание в системе форм общественного сознания имеет ряд отличительных аспектов, которые определяют своеобразные особенности ведения деятельности.

Во-первых, оно имеет комплексный характер, определяющийся своеобразностью отражаемого им объекта. Таким образом, с экологической точки зрения правильно мыслящий человек, должен осознавать не только отдельные события природы, но и понимать экологическую систему в качестве взаимосвязанной сложной ситуациии как одно целое.

Во-вторых, с экологической точки зрения правильное осознание определённого природного объекта или явления, в свою очередь, развивает способность увидеть последствия изменений, происходящих в природе не только в ближайшем будущем, но и в дальнем.

Отличительные черты экологического сознания ярче проявляются в целях его представления. Осознание природы всегда являлось фактором для её активного изменения. В связи с этим, экологическое сознание в определенной степени должно выполнять противоположную функцию, то есть должно 
определять изменения природы на определённых исторических этапах, допущенные человеком на экологических границах.

При этом, нужно привести определение понятия экологическое правосознание учёного правоведа Вершок И.Л. Потому, что в отличие от исследователей, ведущих научные исследования по данным вопросам, определение Вершок И.Л подробно освещает различные аспекты этого явления. В частности, по еe мнению экологическое правовое сознание - это связь с социальным сознанием такими как сила воли, нормативность, право установлением и ее другими формами, основной функциональной задачей которой является влияние знаний и взглядов о природе и окружающей среде на юридические нормы природных ресурсов и охрану окружающей среды, эффективность их использования, использование прав и обязанностей природопользователей и субъектов осуществляющих охрану окружающей среды, выражающих специальный тип формы оптимизации осознания экологических событий и процессов, экологических правовых принципов имеющих юридическое значение [4, с.42].

$$
\text { Таким образом, экологическое }
$$
правосознание в себе отражает экологические правовые взгляды, идеи и представления о правовом регулировании экологических отношений, формы и методы воздействия общества к природе, а также систему оценки, правовых знаний, взглядов, идей и пожеланий по отношению действующих экологическиправовых норм, регулирующих отношения к природе в качестве объекта правовой защиты.

В то же время, изучение юридической природы экологического правосознания, в свою очередь даёт возможность определить следующие его аспекты:

- индивидуальное или общесоциальное внимание к экологическим проблемам;

- осознание роли и значения текущих экологических законодательств, различных социальных институтов и государственных органов в ухудшении состояния окружающей природной среды или, наоборот в решении таковых проблем;

- готовность человека для участия в личном или общественном уровне в изменении существующей экологической ситуации и другие.

Выше указанные обстоятельства, в свою очередь, дают возможность сделать вывод о том, что изучение экологического правосознания, как одну из специальных форм правового сознания в качестве отдельного исследуемого объекта обосновано с теоретической и практической точки зрения.
Правовое образование и пропаганда, направленные на формирование экологического правосознания у граждан должно вестись не только в пределах определённой одной компании, но вестись целенаправленно, запланированно и эффективно, с учётом особенностей различных социальных групп. Для этого необходимо осуществить широкомасштабные работы по заполнению существующих пустот в экологическом законодательстве, по повышению эффективной деятельности правовой поддержки в этой области, по развитию системы обеспечения населения экологической правовой информацией, а также по усовершенствованию средств и методов экологического правового воспитания.

Также вместе с понятием экологическое правосознание, важную роль играет и понятие экологическая культура. Основной идеей экологической культуры является то, что взаимосвязь между человеком и природой должна быть не материальной, а духовной.

Не навредить природе и думать глобально, должно являться обязанностью каждого человека. Чтобы на Земле вечно продолжалась жизнь, человечеству необходимо всегда оберегать свою землю, постоянно омолаживая её и развивая экологическую культуру.

Экологическая культура, в первую очередь начинается с семейного воспитания. Следовательно, в настоящее время развитие экологического мировоззрения, которое становится жизненно важным вопросом тоже является продуктом нравственного воспитания в семье.

Экологическую культуру можно понимать в широком и узком смысле этого слова. В широком смысле слова экологическая культура - это деятельность по охране нашей матушки природы, сознательным отношением к природе, осознавая обязанность и ответственность перед ней. В узком смысле слова это культура охраны окружающей среды каждой личности. Экологическая культура, в первую очередь обязана совмещать в себе экологическое воспитание, экологическое просвещение и экологическую нравственность.

\section{Conclusion}

Резюмируя, можно сказать, что экологическое правосознание и культура, в качестве составной части социального сознания, исходит из преобладающих функций развития международных политико-экологических отношений, сохранения и укрепления стабильного состояния окружающей природной среды в связи с этим, мы считаем брать во внимание следующее: 
- осознавать необходимость безусловного выполнения экологических правовых норм социальных субъектов;

- экологическое правосознание и культура основываются на осознании тесной связи между физической и духовной жизнью человека, а также на понимании, что человек является непосредственной частью природы. При этом человечество должно будет осознавать свою полную связь с природой, признавать необходимость создания социальноэкономических механизмов для осуществления экологических норм, направленных на предотвращение дестабилизации окружающей природной среды и её загрязнения, признавать преимущество защиты окружающей природной среды и обеспечение его стабильности в любом направлении деятельности;

- экологическое правосознание и культура оказывают серьёзное влияние на мотивы принятия определённых решений по поведению людей, имеющее экологическое значение и по их взаимосвязям с природой;
- экологическое правосознание и культура взаимосвязана с принятием экологических правовых информаций у отдельных лиц и социальных групп, с существованием у них отношения к различным экологичеким правовым ситуациям, то есть к законодательству относительно охраны природы, к его требованиям, отношения у государственных органов к деятельности в этой области, а также взаимосвязана с показателем практической деятельности, обеспечивающей взаимозависимость и гармоничность человека и природы.

Резюмируя, можно сказать, "Экология является одной из широкомасштабных острых социальных проблем настоящего времени, их решение соответствует интересам всех народов, настоящее и будущее цивилизации во многом зависит от решения этих проблем." [6, с.507-508]. Так как, одной из великих обязанностей каждого члена общества - это сохранение и рациональное использование природных богатств и защита природы.

\section{References:}

1. Karimov IA (2011) Kontseptsiya dal'neyshego uglubleniya demokraticheskikh reform i formirovaniya grazhdanskogo obshchestva $\mathrm{v}$ strane -vazhnyy etap razvitiya strany. T. 19. Tashkent: Uzbekistan, 2011. - p.109

2. Smirnov TS (1984) Ekologizatsiya soznaniya i ee rol' v optimizatsii vzaimodeystviya obshchestva i prirody (Ekologizatsiya soznaniya vo vzaimodeystvii obshchestva i prirody). - Ivanovo., 1984. - p.74

3. Dolgopolova LD, Dolmatova NI (1981) K teorii issledovaniya prirodookhranitel'nogo pravosoznaniya // Problemy pravovedeniya. 1981. -№42

4. Vershok IL (2003) Ob ekologicheskom pravosoznanii // Gosudarstvo i pravo. 2003. №3. - p.42

5. Karimov IA (1998) Na puti bezopasnosti i stabil'nogo progressa. T.6. - Tashkent: Y̌zbekistan, 1998. - p.109

6. Karimov IA (1999) O`zbekiston buyuk kelajak sari. -T.: O`zbekiston, 1999, 507-508-betlar. 